\title{
Going beyond One-to-One Mediation in Zone of Proximal Development (ZPD): Concurrent and Cumulative Group Dynamic Assessment
}

\author{
Mowla Miri a *, Goudarz Alibakhshi a, Ali Kushki b , Peyman Salehpour \\ Bavarsad ${ }^{\mathrm{C}}$ \\ a Allameh Tabataba'I University, Tehran, Iran \\ ${ }^{b}$ Shiraz University, Shiraz, Iran \\ ${ }^{b}$ Lorestan University, Khoramabad, Iran
}

Received 13 April 2016 | Received in revised form 16 October 2016 | Accepted 30 November 2016

\begin{abstract}
This paper reports on a study delving into the efficiency of two types of Group-Dynamic Assessment (GDA, concurrent and cumulative) in teaching English articles. To this aim, two intact classes of thirdgrade high school students were included in the study and randomly assigned to Cumulative G-DA (n= 34) and Concurrent G-DA $(n=33)$ groups. The homogeneity of the classes was determined and their knowledge of articles, prior to and after the treatment, was measured by administering two parallel cloze tests. G-DA sessions lasted for three sessions, during which both groups worked on three editing tasks on articles according to the operational definitions proposed by Poehner (2009) for G-DA procedures. Results of the study revealed that both types of G-DA increased gains in learning articles. Additionally, it came to light that the concurrent group outperformed the cumulative one. The results are discussed in the light of the tenets of sociocultural theory.
\end{abstract}

(C) 2017 EJAL \& the Authors. Published by Eurasian Journal of Applied Linguistics (EJAL). This is an open-access article distributed under the terms and conditions of the Creative Commons Attribution license (CC BY-NC-ND) (http://creativecommons.org/licenses/by-nc-nd/4.0/).

Keywords: Dynamic Assessment; Group Dynamic Assessment (G-DA); Concurrent and Cumulative GDA; Sociocultural Theory

\section{Introduction}

For long, testing has been and continues to be considered and implemented in separation from teaching enterprise; in fact, static views of testing emphasize silence in testing sessions, during which learners are supposed to, in the absence of any help on the part of their teachers or other peers, demonstrate what they have previously learnt. Teachers, from a static point of view, are mainly concerned with mature or fully developed skills of learners in a retrospective orientation. However, the assessment for learning (henceforth AFL) camp, recently on the up, has endeavored to establish a link between teaching and testing enterprises. One of the branches of AFL, founded on Vygotsky's Sociocultural Theory of the mind (SCT), is Dynamic

\footnotetext{
* Mowla Miri. Tel.: +0-916-712-1168

E-mail address: molamiri84@gmail.com

http://dx.doi.org/...
} 
Assessment (henceforth DA). To quote from Lidz (1987, p. 4), DA is "an interaction between an examiner-as-intervener and a learner-as-active participant, which seeks to estimate the degree of modifiability of the learner and the means by which positive changes in cognitive functioning can be induced and maintained." To meet the objective of such agenda, teachers are required to move away from their inactive and objective position in testing sessions and work as mediators in a dialogic relation with learners (Lantolf \& Poehner, 2004). DA highlights the role of graduated and dialogic mediation tailored to learners' current level of development which can optimally occur in Zone of Proximal Development (ZPD), conceptualized as the space between what learners can perform independently and the level they can reach under the guidance and support of more capable others (Vygotsky, 1978). Through the ZPD space, therefore, we can take account of not only the cycles and maturation processes that have already been completed but also those processes that are currently in a state of formation, that are just beginning to mature and develop (Vygotsky, 1978). To Vygotsky, measuring fully-developed abilities does not reveal any noticeable information about the abilities which are in the process of shaping and becoming. Therefore, in order to offer a more complete picture of both developed and stilldeveloping abilities of learners, they should be involved in a process of dialogic assessment with their teachers. That is, DA shifts the focus from mature and ripe capabilities to examining and nurturing immature and ripening abilities (Poehner \& van Compernolle, 2011).

Indeed, DA was not included in discussions of either L2 assessment or teaching prior to a string of publications by Lantolf and Poehner (Lantolf \& Poehner, 2004; Poehner, 2007, 2008; Poehner \& Lantolf, 2005). From then on, empirical DA studies in L2 setting have appeared in technical L2 journals more. The bulk of reported DA literature has focused on one-on-one DA-based mediation sessions where a teacher and a student dialogically cooperate to find a solution for a linguistic problem which cannot be solely overcome by the student (e.g., Ableeva, 2008, 2010; Poehner and Lantolf, 2010; Rahimi, Kushki, \& Nassaji, 2015). This has led to the misconception that, and actually one of the obstacles to implementing DA in large classes, DA is more appropriate for one-to-one instructional settings rather than for whole classes. Having this in mind, Anton (2009) observes that:

There are some reasons why DA procedures have not been widely adopted in educational settings despite the appeal of providing such rich information on individual learners. One important reason is that DA procedures are ideally administered individually, which makes this type of assessment time-consuming. (p. 579)

Accordingly, "because teachers need to teach the whole class, many public school teachers have had to dismiss the concept as unworkable" (Guk \& Kellog, 2007, p. 281). Therefore, to troubleshoot such a logistical and theoretical problem, Poehner (2009) ventured to introduce Group-Dynamic Assessment (henceforth G-DA) which is principally founded on the pillar of Vygotsky's conception of teacher as a 'tram driver' rather than a 'rickshaw puller'. G-DA attempts to capture the 'group's ZPD'; that is, G-DA aims to involve learners in tasks which learners can only perform by pooling 
their resources together in a dialogic interaction. In spite of its theoretical attraction and solidity, G-DA has been far less explored in the terrain of second language teaching. Therefore, this study set out to narrow down this lacuna by examining two models of G-DA proposed by Poehner (2009), 'concurrent' and 'cumulative' detailed in the following section.

\section{Literature review}

\subsection{Theoretical framework}

DA roots in the ideas of Vygotsky (1978) on the nature of human's mind and social context, recently dubbed as Sociocultural Theory (Lantolf, 2000). SCT is predicated upon the assumption that human beings are associated with and linked to inside and outside worlds in an indirect fashion; that is, we are linked to our internal and external worlds through some socio-culturally constructed artifacts, which are either symbolic (e.g., language, literacy and music) or physical (e.g., paper and pencil). Another type of mediation which lies at the heart of SCT is social interaction. Vygotsky (1978), in his genetic law of development, posited that "Every function in the child's cultural development appears twice: first, on the social level, and later, on the individual level; first, between people (interpsychological), and then inside the child (intrapsychological)" (p. 57). Ohta (2000) maintains 'Meaningful social interaction functions as a mechanism through which the transformation of L2 from interpsychological to intrapsychological functioning occurs' (p. 54). Given this, it can be arguably said that every kind of knowledge, including linguistic one, is originally co-constructed via involvement in social interaction with other human beings or self (e.g., private speech). Later on, the co-built knowledge at social or interpsychological level is internalized or taken in by the individual and stored at the intrapsychological plane (Vygotsky, 1978).

To Vygotsky, learners are neither fully independent nor utterly reliant, but they need the help of more capable others in order to build upon their current level of capabilities and promote within Zone of Proximal Development (ZPD), "the distance between the actual developmental level as determined by independent problem solving and the level of potential development as determined through problem solving under adult guidance or in collaboration with more capable peers" $(1978, \mathrm{p}$. 86). It is worth noting that ZPD is conceived of as an influx learner's trait rather that a predetermined fixed one which is unveiled and shaped by involving the learner in a dialogic and interactive relationship (Wells, 1999).

Vygotskyian-inspired SCT posits that the optimal time for diagnosing learners' hesitations, gaps, and holes in their developing interlanguage and offering an agenda for development can be determined only through interaction with the learners in their ZPDs; thus, the learners must be scaffolded according to their real needs and lacks. Scaffolding, as a mainstay of SCT, is defined as a "situation where a knowledgeable participant can create supportive conditions in which the novice can participate, and 
extends his or her current skills and knowledge to higher levels of competence" (Donato, 1994, p. 40). In fact, the learners and teachers or more capable peers pin down the required feedback when engaged in a dialogic interaction.

\title{
2.2. Dynamic assessment
}

Dynamic assessment intends to capture learners' level of actual development and their level of potential development. DA is grounded in Vygotsky's thoughts that learning (i.e. performance with the help of others) is a precursor to development (i.e. what learners can do independent of others) and development is contingent on learning; therefore, effective assessment should take both learning and development into account. Vygotsky (1978) asserted that:

Learning awakens a variety of internal developmental processes that are able to operate only when the child is interacting with people in his environment and in cooperation with his peers. Once these processes are internalized, they become part of the child's independent developmental achievement. (p. 90)

In contrast to non-dynamic assessment which mainly focused on fully ripen abilities, DA tries to unravel the abilities which are in the process of shaping and ripening (Lantolf \& Poehner, 2004). Lantolf and Poehner (2004) assert that:

\begin{abstract}
DA integrates assessment and instruction into a seamless, unified activity aimed at promoting learner development through appropriate forms of mediation that are sensitive to the individual's (or in some cases a group's) current abilities. In essence, DA is a procedure for simultaneously assessing and promoting development that take account of the individual's (or group's) zone of proximal development. (p. 50)
\end{abstract}

Due to this shift in roles and objectives of assessment, assessors' roles are consequently redefined within the framework of DA. The assessors shall work as mediators trying to interact with learners in their ZPDs to diagnose their actual and potential levels and concurrently extend their existing knowledge by providing attuned and calibrated feedback. Albeeva (2008) highlights that "the goal of DA is to reveal learners' potential future development on the intermental plane and to help it develop on the intramental plane through mediator-learner interaction" (p. 62). However, traditional static assessment which stems from psychometric principles stresses that any intervention on the part of teachers during test administration is a potential threat to the fundamental tenets of testing, especially reliability (Poehner \& Lantolf, 2005). "As called for in Vygotsky's ZPD, assessment and instruction are dialectically integrated as the means to move towards an always emergent (i.e., dynamic) future, rather than a fixed and stable steady state" (Poehner \& Lantolf, 2005, pp. 237-8).

\subsection{Group-dynamic assessment (G-DA)}

It is apt to assert that both one-to-one and G-DA are constructed on the basis of mediation within learners' ZPDs to co-construct knowledge; however, in G-DA, an attempt is made to take all participants' ZPDs into consideration (Poehner, 2009). 
Poehner (2009) resorted to Petrovsky's (1985) conception of group and asserted that group is construed as a social activity in which individuals pool their resources together to cooperatively or unanimously meet their goals. That is, individual members realize that for successful fulfillment of their objective, they should depend on one another to move beyond their solo capabilities.

It seems that providing an explanation of some key concepts of G-DA such as individual-group link, primary-secondary interactants, and private speech is in order. Expounding the relationship between the development of individuals and that of a group, or the development of the individual's and the group's ZPD (Poehner, 2009), Petrovsky (1985) lists three types of individual-group links: group-as-context, groupas-cooperation, and group-as-collective. Group-as-context is reductionist in that every attempt is made to separate the performance of the individual from that of the group so as to assess it in the context of the group. The other two approaches to the individual-group link are different from the first one since they see the group "to have psychological status and stress the importance of the activity in which group members are engaged.” (Poehner, 2009, p. 474). In group-as-cooperation, still the individual pursues his/her own goals while recognizing that the goals are interrelated with those pursued by the other group members. In group-as-collective, the individual and the group unanimously work toward a common goal (Poehner, 2009). The statistically significant gains, as shown by the learners' enhanced post-test performance, in both cumulative and concurrent G-DA approaches in the study might have been due to the establishment of this group-as-cooperation atmosphere where the individual students pooled their mental efforts in a "joint mental activity" (Petrovsky, 1985, p. 183) to develop their understanding of the target forms, i.e., English articles.

This pooling of mental abilities during a "joint mental activity", as suggested by Petrovsky (1985), which pushes forwards the group's and the individual's ZPD simultaneously is made possible through learners taking the role of primary and secondary interactants during G-DA-run sessions. According to Poehner (2009), during an event when the teacher mediates a given learner's difficulty, that learner and the teacher are considered as primary interactants since they negotiate the support that is needed. However, "because the exchange occurs in the social space of the class and before the other group members, it has mediating potential for the rest of the group as well, who are secondary interactants but participants nonetheless" (Poehner, 2009, p. 477).

Therefore, to realize G-DA, learners should be engaged in tasks that they individually fail to accomplish but are achievable whenever they put their forces together. Poehner (2009) drew a distinction between Concurrent and Cumulative GDA. However, before introducing these two terms, the concept of primary and secondary interactants should be delineated. When teacher offers a mediation in response to a learner's incompetence to meet his/her purpose independently, the teacher and the learner are conceived as primary interactants; nevertheless, since collaboration occurs at social plane of the classroom before all classroom members, other learners are exposed to the collaborative dialogue and can benefit from it; thus, 
they are considered as secondary interactants. In the case of concurrent G-DA, the interaction between the primary interactants might be directed to the secondary interactants when one learner, addressed participants, cannot respond to the provided mediation. In fact, the failure of the addressed learner leads to bringing other learners into play once considered as secondary participants. In contrast to concurrent G-DA in which addressed learners do not receive in-depth interaction from the primary mediator, in cumulative G-DA, "the teacher conducts a series of one-on-one DA interactions as the group works toward mastery of a problem" (Poehner, 2009).

\begin{abstract}
That is, individuals take turns engaging directly as primary interactants with the teacher, with the understanding that each subsequent one-on-one exchange will have the advantage of building on earlier interactions that the class witnessed. This approach is cumulative in that the goal is to move the entire group forward in its ZPD through negotiations with individual learners in their respective ZPDs. Cumulative G-DA attempts to move the group forward through co-constructing ZPDs with individuals, but concurrent G-DA supports the development of each individual by working within the group's ZPD. (p. 478)
\end{abstract}

\title{
2.4. Empirical studies on $G-D A$
}

Driven mainly by the ambiguous nature of how sociolinguistic variation can be taught and learned in classroom contexts and the meager role considered for collaborative teaching-learning activity to play in between, van Compernolle and Williams (2012) involved a university class of intermediate L2 French learners in a group zone of proximal development (ZPD) during instructional conversations (ICs). The purpose was to see how co-creation of a class ZPD between the teacher and students through collaboration helped microgenetic developments in the learners' conceptual understanding of sociolinguistic variation in French operationalized in terms of how the sociolinguistic features of the pronoun on, second-person pronoun $t u$ and vous, and ne (i.e., the verbal negation) realize across a formality continuum. Through group ZPDs during ICs, the researchers documented microgenetic developments in the form of important qualitative shifts in the students' conceptual understanding of the studied sociolinguistic features. The researchers draw the conclusion that providing teaching within a group's ZPD potentially can result in a more profound and conceptually based take on language variation in French.

van Compernolle and Williams (2013) reported that the meticulous analysis of a video-recorded small-group interaction to empirically see how a collective ZPD works in an EFL classroom. The researchers indicated how Diane, one of the participants of the group reported in the study, engaged in the active reception of her group mates' discussions and problem solving regarding the point at hand through embodied participation. Drawing on the concept of primary and secondary interactants in a collaborative activity, they showed how Diane as a secondary interactant benefited and followed members of the group through eye gazes and repeated nodding, indicating Diane's active engagement in the group's discussion. Through this embodied participation Diane could switch from a secondary interactant to a primary one, providing her contribution verbally to the group's discussions and problem solving. van Compernolle and Williams claimed that this is an important event since 
Diane's benefitting from her group mates' talk "precisely what is meant by a group or collective ZPD in Vygotskian research - as the group develops through collaborative interaction, so do its individual members" (p. 17). The analysis shows how a collaborative talk benefits all members of a group even those non-speaking; van Compernolle and Williams (2013) to take an expansionist orientation to EFL classroom ZPD. The researchers expand the concept of participation wide enough to include non-verbal or embodied participation in addition to the verbal interactions and contributions of all members of a collaborative activity.

In an attempt to assign a 'tram driver' role to teachers in favor of a 'rickshaw' one, Guk and Kellogg (2007) conducted a study to see how a whole-class ZPD can be established through a two-stage process. During the first stage the teacher mediated a task for a number of learners. Then, each of the teacher-mediated learners mediated other learners in their own groups. In fact, Guk and Kellogg' purpose was to understand whether teacher- and student-led interactional mediation of tasks showed different features so as to consider two different ZPDs based on the interactional mediation features. Guk and Kellogg (2007) empirically show that "the way in which learners mediate tasks differs from the way in which teachers do, and argue that this suggests learner-to-learner mediation is in important ways closer to what Vygotsky termed internalization" (p. 281). For example, findings of the study indicated that S-S interactions S-S interactional mediation had a lower proportion but higher absolute number of learner utterances in English. The researchers conclude that instead of interpreting T-S and S-S interactional mediation differences as an indication of two distinguishable ZPDs, "both teacher-led mediation and learner-to-learner interaction may be considered waystages within a single whole classroom ZPD” (p. 287).

Examining the role of concurrent GDA in enhancing listening comprehension and metacognitive awareness of listening strategies was the focus of a study carried out by Moradian and Baharvand (2015). Results of their study indicated that GDA could significantly enhance gains in both listening comprehension and metacognitive awareness of listening strategies.

Moreover, Kao (2015) explored the efficiency of interactionist DA in developing Chinese rhetorical structures. Results of the study indicated that interactionist DA led to development in the target forms. However, the study was restrained to a small group of three students that lessened the generalizability of the findings. Also, lack of a control group prevented comparability of interactive DA with non-DA method.

\subsection{Purpose of the study and research questions}

Most of the studies on DA, as pointed out by Poehner (2009), have focused on individual tutoring rather than on ZDPs of class participants. Thus, one of the issues that have obstructed DA to find its way into EFL classrooms is ELT practitioners' doubts and reservations about its applicability and efficiency in engaging ZPDs of large classrooms. That is, it is construed as best applicable to individual tutoring (Anton, 2009). However, Poehner (2009) has provided some evidence for the efficacy of 
two types of G-DA in teaching EFL. He postulated that "for G-DA to effectively promote the development of all group members, the teacher must actively engage the entire group in G-DA interactions" (p. 477). As noted earlier, two types of G-DA were proposed and some pieces of evidence for efficiency of each were put forward but no argument for the superiority of one over another is made. Davin (2011) claims that:

\begin{abstract}
It seems that this one-on-one interaction with a single student would cause less anxiety than the concurrent approach in which the teacher dialogues with the entire group. Concurrent DA seems to lower the confidence of a student who does not get the opportunity to offer a second response, therefore ignoring the resulting interaction and never knowing what the correct answer was ( $\mathrm{p}$. 29).
\end{abstract}

However, no empirical attempts have been made to compare the efficiency of these two types of G-DA, concurrent and cumulative, in language teaching. Additionally, as pointed out by Davin (2011), "the majority of DA studies in foreign language education have focused on university students. Up to now, only one study has examined the implementation of DA with a group of students in a foreign language classroom" (p. 7). Therefore, this study implemented two types of G-DA in two intact classes of state high schools in Iran so as to contribute to the growing G-DA literature. More specifically, this study was driven by seeking an answer to the following questions:

1. Does engaging learners in concurrent G-DA result in any significant gains in English articles?

2. Does involving learners in cumulative G-DA lead to any significant gains in English articles?

3. Do cumulative and concurrent G-DA differ in enhancing gains in English articles?

4. Which insights were yielded by the participants about when they served as secondary participants in either cumulative or concurrent group?

\title{
3. Method
}

\subsection{Research design}

This study adopted a pre-test and post-test design. Initially, a non-dynamic pre-test was held, then, G-DA enrichment sessions were sandwiched in between and finally, the non-dynamic post-test was administered. Each group received three G-DA enrichment sessions according to the operational definitions of G-DA types, concurrent and cumulative. The purpose of the pre-test phase was twofold: to document the learners' current developmental level of English articles and their baseline knowledge and to base enrichment sessions on it. The post-test phase helped the researchers understand whether there was a change in the learners' understanding of the articles the study targeted on.

\subsection{Setting and participants}


This study was conducted in a public school in the context of Iran, in which learners are mainly assessed according to paper-and-pencil tests with no experience of DAbased assessment procedures. In such a context, English is taught as an obligatory subject for 75 minutes a week. Besides, teachers rule classrooms and the central focus of these classes is mainly on reading, vocabulary, and grammar to the exclusion of listening, speaking and writing. In addition, reading practices are translation tasks as such; that is, the teacher primarily reads out the text sentence by sentence and translates it into the learners' L1, Persian, while the learners only write down the translations between the lines of the texts or in their notebooks. Further, grammar teaching is practically synonymous with metalinguistic elaboration of grammatical points on the part of the teacher. Concerning vocabulary instruction, it is worthy to highlight that the most prevalently practiced way is offering L1 equivalents for the words given in a list at the end of lessons.

Two intact classes of Iranian EFL learners participated in the current study: concurrent $(n=33)$ and cumulative $(n=34)$. They were all male aged between $15-17$. Though the researchers could not reshuffle the combination of the classes, the classes were assigned to concurrent and cumulative groups at random. The learners had the course with the first researcher (Teacher researcher) at the time of the study. Of note here is that though these classes were in the same grade of high-schools and had passed the same nationwide course-books, their homogeneity was assessed according to teacher evaluation and a teacher made test.

\subsection{Target forms}

The study focused on English articles only. Following Nassaji and Swain (2000), we defined English articles as the three instances of articles in English, namely definite article (the), indefinite articles (a/an), and zero articles $(\Phi)$. Articles are distinguished by the fact that whether they and their associated noun phrases refer to "a specific entity [ \pm specific referent] and whether the article and the associated NP are deemed to be already known (from the previous discourse or from context) to the listener [ \pm hearer knowledge]" (Shintani, Ellis, \& Suzuki, 2013, p. 111).

These structures were chosen on a number of grounds. For a start, hands-on experience of the researchers substantiated that even advanced Iranian EFL learners have either problems with articles or overgeneralize use of the definite article. This is in line with the fact that students across English language proficiency levels experience difficulty in the use of the English article system (Bitchener \& Knotch, 2010; Bitchener, Young, \& Cameron, 2005; Butler, 2002; Master, 1995). For example, they may experience di culty deciding whether an article is required and, if it is required, whether it should be the definite or indefinite article. Moreover, according to Sheen (2007), it helps isolate the effect of error correction from any potential effect of grammar instruction in general as like the participants of Sheen's study, the participants in the present study (a) were not explicitly taught articles during the semester, and (b) articles, though constituting a structure where students commonly 
make errors, are infrequently corrected because they are nonsalient and they require complicated rule explanations. This is ironical as the SLA literature has clearly shown that English articles are considered to be a nonsalient feature.

Furthermore, learners have been observed to experience difficulty in learning articles because of their complex nature; that is, the choice of an article is determined by both linguistic and pragmatic factors (Butler, 2002; Liu \& Gleason, 2002). Moreover, according to Storch (2010), to accurately measure changes in accuracy in response to corrective feedback, researchers would need to trace each type of error which received feedback. This is only feasible if the feedback is confined to a limited range of errors. Also, articles will be targeted at since Ferris (1999) suggests that feedback may be most effective if it focuses on what she terms 'treatable' errors. Treatable errors (e.g. verb tense and form, subject-verb agreement, article usage) occur in a rule-governed way, and may therefore be more amenable to feedback and self-correction. Additionally, as reported in Shintani et al., (2013), previous research evidenced that articles are learned very late.

It is worth highlighting that the structure was a part of the syllabus covered in class. The teacher researcher realized that majority of the students had problems with some structures such as articles taught previously, so, before the students' final exams, he devoted seven sessions to working on the structures. Among the seven sessions, three were allotted to working on articles.

\subsection{Tests}

To measure both groups' knowledge of the articles prior to and after the interventions, two cloze tests, each comprising 15 blanks on articles, were utilized. To develop these tests, the ensuing measures were undertaken. Firstly, two passages from the regular textbook of the participants which were of the same length and reading difficulty were selected. The passages were adopted from the participants' regular textbooks since it was hypothesized that the participants could take them more seriously because of their close relevance to their educational programs. Furthermore, the participants considered them as a part of their regular educational program, so the ecological validity of the study was acceptably high. Secondly, the researchers developed five blanks for each of the three article types, a total of 15 banks. Measures were taken to assure that only one of the articles was correct in each context. Thirdly, the tests were piloted with a group of students $(n=29)$ who were homogenous with the participants in terms of language proficiency, gender, and socioeconomic background. Results of the pilot study indicated that the tests were parallel.

\subsection{Tasks}

Three editing tasks were used in the course of intervention sessions. The tasks were developed on the basis of three texts adopted from the participants' 
regular course books. The following measures were undertaken to design the tasks. Initially, three reading passages containing about 200 words from the participants' textbook were chosen, following which 15 article situations were modified, five for each of article types. Afterwards, task instructions were developed and the tasks were piloted with the group taking the tests. In fact, they were asked to carry out the tasks and to comment on the problems they faced. In light of the pilot study results, some minor modifications were made to the tasks. In each intervention session, the groups worked on one of the tasks.

\subsection{Semi-structured interview and stimulated recall session}

In order to depict a more detailed picture of how the learners in both groups responded and engaged in classroom dialogues, a semi-structured interview was held immediately after the post-tests by one of the researchers. Semi-structured interviews were utilized on the following grounds: it can help us obtain an insider or 'emic' insight into the processes the learners undertook so as to internalize the coconstructed knowledge at a social plane or what caused their failure to appropriate it. Further, due to its interactive nature, the semi-structured interview can assist us to extract "additional data if initial answers are vague, incomplete, off-topic, or not specific enough" (Mackey \& Gass, 2005, p. 173). In order to remove the concerns with learners' proficiency level which might adversely affect the quantity and quality of the collected data, the interviews were held in the learners' L1, Farsi. Moreover, to develop a more nuanced understanding into the participants' experiences of G-DA sessions, stimulated recall was utilized. More precisely put, learners' video-recordings of the sessions were displayed through a video-projector and, then, the learners were asked to comment on their moves in specific moments. The vide-recordings could provide them with rich and strong stimulus to retrieve what they were doing and thinking in the course of the intervention sessions. Like the semi-structured interviews, the stimulated recall session was held in the participants' L1.

Of note is that all interviews and stimulated recall sessions were audio-recorded and transcribed verbatim by the researchers. Then, the first and third researchers made use of the methodology of content analysis as to extract the recurrent themes (Dornyei, 2007). More precisely, each of them read the transcripts several times so as to get familiar with the data. Then they each of them read the transcripts again and highlighted the themes and labeled them. Afterwards, each of them listed the labeled themes, reviewed the list several time so as to find the links among the codes and cluster them. Finally, both coders sat together and discussed their differences to reach complete consensus.

\subsection{Field notes}

The teacher-researcher took detailed field-notes on learners' behaviors as he was working with the learners on editing tasks through ZPD-sensitive feedback. More 
specifically, immediately after each treatment session the teacher researcher stayed in school and wrote down all noticeable points in detail. Then, he transcribed the audio-recorded files of dialogues at home and synchronized the field-notes and transcriptions. As pointed out by McDonough and McDonough (1997), combining field notes and observation transcriptions "represents a move away from reductionist observation methods towards one might usefully call elaborative description" (p. 112). The field notes then were analyzed through the methodology of content analysis by the first and third researcher (Dornyei, 2007).

\subsection{Procedures}

At the outset of the study, both groups' knowledge of articles was measured by running the pre-test. It lasted 30 minutes for both groups. In the subsequent three sessions, the groups worked on the same three editing tasks within the framework of G-DA. More precisely, the learners were initially asked to do the revision task individually in a quarter. Meanwhile, the teacher wrote the editing text on the board to let all learners jointly direct their looks and attention to the same point. Afterwards, the teacher called on one of the students to come to the board and transfer his answer to the text on the board. Then, the teacher tried to enhance both the learner's along with whole class ZPD by taking the following approaches: in concurrent G-DA class, the teacher researcher asked the learner to read out the text while he afforded graduated feedback to him whenever he failed to rectify the existing problems with the text. In such a case, the teacher initially asked the learner to read the line containing the error more carefully; then, if he failed to detect the error, the teacher researcher uttered the phrase containing the error in a rising intonation. If the learner was still unable to figure out the problem, the teacher researcher called on another learner to identify and rectify the problem. In the case of the second learner's failure, the teacher researcher offered a more explicit feedback or gave an either/or option, for example the or a/an. In the case that the second learner was also unable to respond, the teacher researcher brought another learner into the scene. In fact, different learners were recruited at the same time to co-construct the correct response which individual learners were unable to achieve. This excerpt taken from intervention sessions for concurrent G-DA showcases how the teacher researcher engages various students to resolve one problem.

Excerpt 1: Dialogic feedback for concurrent G-DA

$1 \mathrm{~S}:$ In other words, we do not educate the children.

$2 \mathrm{~T}$ : Do you see any problem with the sentence?

3 Shayan: Um ... (5 seconds)

$4 \mathrm{~T}$ : the children?^

5 Shayan: No problem.

6 T: Do we need THE here Babak?

7 Babak: I think yes. 
$8 \mathrm{~T}$ : Yes?^ Why?

9 Babak: Sir children maloomeh. (children is known.)

10 T: Mehran! Is children known?

11 Mehran: We don't need the. esme aame (It's a general noun.)

12 T: Bravo. We educate all children. Children in Tehran. Children in Karaj. Childern in any part of our country. Go ahead Shayan.

As seen, initially Shayan comes to the board and reads out one segment of the editing task. Then the teacher researcher tries to raise his attention by posing an implicit prompt, which is a general question; however, Shayan is unable to detect the problem, so the teacher tailors the prompt and provides him with a more explicit prompt (turn 4). Yet, Shayan cannot detect the source of problem. Realizing Shayan's inability to address the problem, the teacher makes the prompt even more explicit and brings Babak into the multi-party play (turn 6). The teacher in fact pronounces 'THE' more emphatically to pinpoint the root cause of the problem. Bakak's answer together with his justification is indicative of his inability to fix the problem with the sentence, so the teacher researcher tries to construct a collective ZPD by addressing a more explicit prompt to Mehran. Finally, Mehran explicates the source of problem, yet the teacher elaborates on Mehran's contribution to help the students get a deepened insight into the reasons underlying the problem.

In contrast to addressing and employing various learners to co-build a correct answer, only one student for each editing task was addressed in the cumulative group. Specifically put, when one of the learners was asked to come to the board, the teacher researcher went through a gamut of feedbacks to assist him with detecting and eliminating article errors. In fact, other learners sitting were not addressed to offer their ideas. The following excerpt portrays how graduated feedback was offered to the cumulative group.

1 Amir: In other words, we do not educate the children.

2 T: Do you see any problem with this sentence?

3 Amir: It's correct.

4 T: The children Amir!

5 Amir: OK!

6 T: Do we need THE?

7 Amir: Aha! No. esme namoshakhase. (It's an unknown noun.)

8 T: Right. We should delete the. Go ahead please!

As this excerpt vividly indicates, the dialogic discussion has only two parties, Amir and the teacher in which the teacher starts with the most implicit prompt and then makes his feedback more and more explicit so as to assist Amir to detect and resolve the problem. In fact, the other students are not called upon to contribute to the dialogic discussion between Amir and the teacher; however, they are functioning as unaddressed or secondary participants. 
Finally, after three intervention sessions, the post-test was administered to both groups and the semi-structured interview was held to delve into learners' views about G-DA sessions. Three days after the post-test, the stimulated recall sessions were held.

\subsection{Data Analysis}

Independent-samples t-test was used to compare the concurrent and cumulative groups' performances to each other. In order to compare performance of each of the groups' pre- and post-test performances, paired-samples t-test was run.

\section{Results}

\subsection{Results of quantitative data analysis}

The first and second research questions sought to find if exposing the participants to concurrent and cumulative G-DA approaches resulted in their improved performance in the post-tests in comparison to the pre-tests (Table 1 and 2). For this purpose, the pre- and post-test performances for each group were compared by running two paired-samples t-test.

Table 1. Descriptive statistics for comparing the pre- and post-test of each of the groups

\begin{tabular}{llllll}
\hline & & Mean & $\mathrm{N}$ & Std. Deviation & Std. Error Mean \\
\hline Pair 1 & pre-test of concurrent G & 3.78 & 33 & 1.13 & .19 \\
& post-test of concurrent & 9.27 & 33 & 1.25 & .21 \\
\multirow{2}{*}{ Pair 2} & pre-test of cumulative & 3.88 & 34 & 1.12 & .19 \\
& post-test of cumulative & 7.26 & 34 & 2.68 & .46 \\
\hline
\end{tabular}

Findings for the concurrent group showed a statistically significant increase in gains from the pre-test $(M=3.78, S D=1.13)$ to the post-test $(\mathrm{M}=9.27, \mathrm{SD}=1.25), \mathrm{t}$ $(32)=-28.82, \mathrm{p}<.000$. Additionally, the eta squared statistic (.96) indicated a very large effect size. Also, the results of the paired-samples t-test for the cumulative group indicated a statistically significant increase in scores from the pre-test ( $M=3.88$, SD $=1.12)$ to the post-test $(\mathrm{M}=7.26, \mathrm{SD}=2.68), \mathrm{t}(33)=-7.25, \mathrm{p}<.000$. Eta squared statistic (.61) for the cumulative group indicated a large effect size. That is, the increase in the post-test scores for both groups was not only significant but also meaningful. Further, the gains could be associated to the effect of independent variable (i.e., instructional interventions) on learning articles rather than intervening variables. 
Table 2. Inferential statistics comparing the pre-and post-test scores of each group

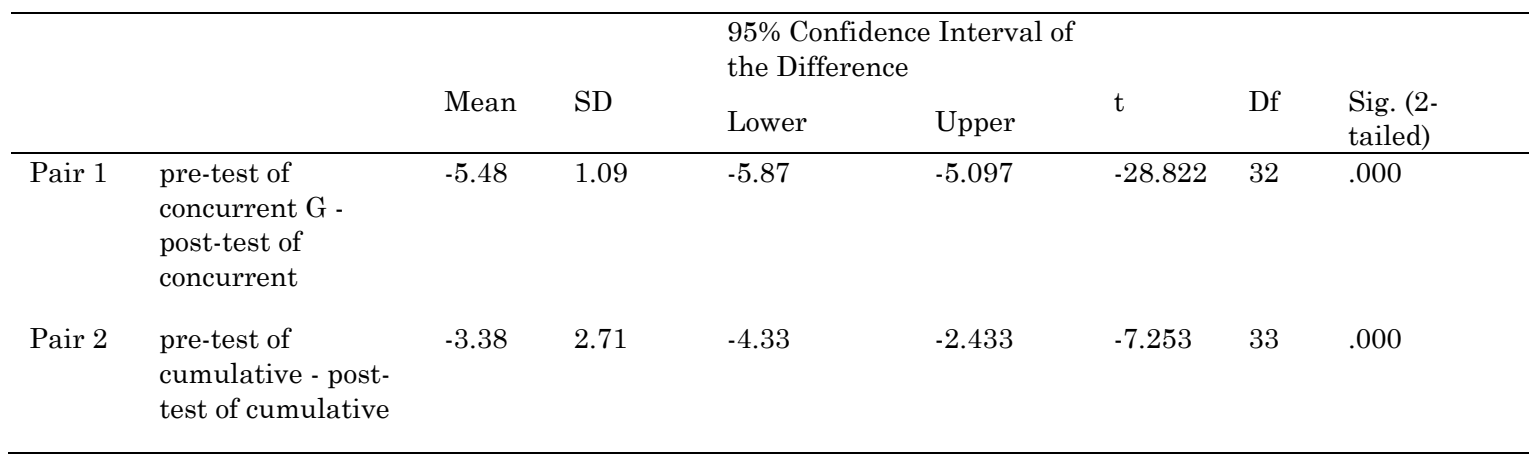

The third research question aimed at comparing the role of cumulative and concurrent G-DA in learning articles. To this aim, an independent-samples t-test was conducted on the post-test scores for both groups. As portrayed in Table 3, descriptive statistics were indicative of a mean difference between the cumulative and concurrent groups.

Table 3. Independent samples t-test for comparing cumulative and concurrent post-test performances

\begin{tabular}{llllllll}
\hline G-DA type & $\mathrm{N}$ & Mean & $\begin{array}{l}\text { Std. } \\
\text { Deviation }\end{array}$ & $\begin{array}{l}\text { Std. Error } \\
\text { Mean }\end{array}$ & $\mathrm{t}$ & $\mathrm{Df}$ & Sig. (2-tailed) \\
\hline Concurrent & 33 & 9.27 & 1.25 & .21 & 3.93 & 47.06 & .00 \\
Cumulative & 34 & 7.26 & 2.68 & .46 & & & \\
\hline
\end{tabular}

The results demonstrated that there was a statistically significant difference in scores for the cumulative group $(\mathrm{M}=7.26, \mathrm{SD}=2.68)$ and the concurrent group $(\mathrm{M}=9.27$, $\mathrm{SD}=1.25 ; \mathrm{t}(65)=3.93, \mathrm{p}<.000)$. Additionally, the magnitude of the differences, effect size, calculated by eta squared statistic was found to be very large (.19). That is, the difference was not only significant but also meaningful.

\subsection{Results of qualitative data analysis}

The fourth question intended to delve into the ways that serving as secondary participants could benefit from the interactions exchanged between the primary interactants. To obtain an insider view into this issue, the results of the interviews, stimulated-recall sessions, and field-notes were taken into account. The content analysis revealed that the secondary participants in each of the groups could benefit from the interactions occurring in their social milieu as far as they served as active recipients. Active reception was actualized through verbal (i.e., private speech) or nonverbal participation (i.e., gazing and head-turning).

The role of some forms of private speech, vicarious response, imitation, and silent talk, was recurrently highlighted by the participants in the concurrent group. Amir (all names given are pseudonyms), for instance, uttered that: 
Whenever, you [the teacher researcher] asked a question, I answered the question in a very soft voice or in my mind. As you know, like some of the students, I had some problems with using 'the' in appropriate context, so whenever I noticed that your dialogues were concerned with my problems I followed your dialogues more attentively. I was also on alert and looked closely at the person whom you posed the question to. In fact, I listened carefully since I thought that I am the next student who would be called upon. It was like a game when you offered help step by step not all at once.

Clearly expressed, the episode affirms Amir's involvement in vicarious response where he says "... I answered the question in a very soft voice or in my mind." Hence, it can be argued that through this active but covert participation, Amir tried to regulate and internalize the knowledge co-constructed on an inter-personal level. Furthermore, the excerpt shows that Amir was not a passive recipient of the information he was exposed to; even he paid closer attention when he realized that the addressed student's problem was similar to his and the offered feedback was in line with his needs. In a similar vein, Parsa noted that:

I tried to follow your dialogue with students who came to the board, since I thought I could learn from your conversation with the students. Further, I followed the dialogues in order to help him overcome his problems. Class is for all. By the way, I was talking to myself or writing down the explanations that seemed useful. Furthermore, I tried to compare the student's answer on the board with my own answers so I always shifted my eyes from my own sheet to the board and other students whom you addressed.

Parsa's words, too, attested that he has actively tried to participate in dialogues occurring at the social level of the classroom through bodily contributions (e.g., eyeshifting) and private speech (...was talking to myself or writing down the explanations that seemed useful). While comparing his answers with those exchanged between the primary interactants, Parsa drew upon silent or inner speech, too. That is, he was talking in his mind with a voice that could not be socially heard. This inner talk to oneself can help learners obtain more control over what they are learning and move toward self-regulated performance (Lantolf \& Thorne, 2006).

The role of imitation was also recurrently highlighted. As a good case in point, Shayan remarked that:

I tried to maintain my concentration by repeating your talk and other students in a low tone of voice or inside my mind. In this way, I could stay in the picture because I could be next person to be called upon by you. In fact, I could understand what was discussed and what we should talk about afterwards.

DiCamilla and Anton (2004) asserted that imitation or repetition can help learners establish and maintain a shared perspective of the task (i.e., intersubjectivity). Similarly, Anani Sarab and Gordani (2015) noted that private speech can assist learners to focus their attention on the task at hand and avoid distractions.

One of the factors that could play a role in stimulating secondary interactants in concurrent group to be more active was the format of giving feedback. In fact, in concurrent G-DA, ZPD-oriented turns are not restricted to one learner, but the teacher calls upon various learners to co-construct a collective ZPD and resolve the problem at hand, and consequently, the learners are pushed to be on alert. This point was recurrently raised by a large number of the learners $(n=23)$ in the interview and 
stimulated recall sessions. In the stimulated recall session, Hadi, for example, stated that:

To be honest, I have got a very bad habit. I don't listen carefully in class since I think I can learn by reading my lessons at home, but in your class I had to listen closely since your questions compelled me to follow everything. I was ready since I thought that I would be the next who would be called upon. Thus, I answered almost all questions you posed to my classmates in order to be ready for probable questions directed to me.

While concurrent G-DA could engage the learners in active verbal and non-verbal participation, a noticeable number of the learners in cumulative group $(\mathrm{n}=19)$ asserted that they frequently failed to remain actively engaged in the dialogues between the primary interactants. This decrease in the level of engagement for the cumulative group can be related to the fact that the teacher researcher in cumulative group called upon one student during working on each task, so the unaddressed or secondary students, comprising the main portion of the class, failed to continuously follow classroom dialogues. The point was substantiated by Farhad:

I think you can learn whenever you listen. I talked to my classmate whenever you were involved talking to the student coming to the board since I was sure that you would not ask me in that session.

Mohsen also verified this point, revealing that:

I listened a little and, in fact, didn't pay attention to the person who came to the board. I thought that you only intended to help the students coming to the board. Sir! I wish I had listened.

This excerpt from the semi-structured interview unveils some of the reasons behind Mohsen and other students' failure to benefit from ZPD-sensitive feedback given to the addressed participants. In actual fact, they failed to realign their objectives to actively participate in classroom dialogues by either verbal or non-verbal languages.

However, the learners in the cumulative group who pointed out that they followed the exchanged dialogues between the primary interactants or involved in private speech benefited much more from the enrichment sessions. As a good case in point, Parham whose performance was improved by 7 scores remarked that:

\footnotetext{
.... at the beginning I didn't listened to the dialogue between you and the students coming to the board attentively, but then I realized that I could learn a lot since I myself had the same problems. I put myself in other students' shoes and answered your questions in a rather low voice. I tried to compare my own answers with others students as well since I liked to correct my errors. To do so, I can say that my look was commuting between the board and my own paper.
}

As viewed, Parham's words support the point that he has been an active recipient during the enrichment sessions. Stimulated recall session revealed that his participation was realized by verbal (i.e., vicarious response) and non-verbal language (i.e., gazing and eye-shifting). This means that Parham was an agent of his active participation in class ZPD. He realigned his objectives with class ZPD and benefited from the graduated feedback negotiated between primary interactants in his sociocultural context. This resonates with van Compernolle and Williams's (2013) point that learners do not profit from being placed in a group, what is referred to as group 
as context (Petrovsky, 1985), but the learners should reconstruct and reconsider group as a psychological unit. In other words, physical closeness is just a point of departure for rebuilding group as a psychological unit. In a word, "For learners to benefit from group work, they must participate in it" in one way or another (van Compernolle \& Williams, 2013).

Additionally, video-recordings and field notes of the teacher researcher documented that calling upon the learners in concurrent group made them turn their heads towards the addressed student and the teacher researcher. Put exactly, secondary interactants looks were going back and forth between the teacher and the addressed learner. One tangible example for embodied participation was when one of the learners at the back row was addressed and learners in the front row had to turn their heads to follow the discussion. In contrast, as video-recordings evidenced, a large number of the learners in cumulative group did not follow the dialogues between the primary interactants and were busy chatting to their classmates. As the results of semi-structured interview suggested they hypothesized that the dialogues are only appropriate for addressed participants.

\section{Discussion}

As noted, the first and second research questions of the study sought to explore if application of concurrent and cumulative G-DA would result in an enhanced understanding of English articles in a group of Iranian high school students as determined by comparing the students' pre- and post-test performances. Results of the study indicated a statistically significant increase in the students' knowledge of the English articles for both cumulative and concurrent $(\mathrm{p}<.000)$ G-DA approaches. The gains in the results can be explicated by the time when the participants in each of the groups served as primary or secondary interactants.

Whenever the participants were afforded opportunities to directly interact with the teacher as primary interactants, they received graduated feedback tailored to their level of need within their co-shaped ZPD. This ZPD-sensitive feedback occurring in a dialogic context could have enabled the primary participants to diagnose their problems and jointly co-build further knowledge about the articles, and consequently go beyond the current level of their capabilities (Lantolf \& Poehner, 2014). That is, as noted by Poehner (2009), they could have managed to internalize the co-built knowledge and implement it individually. This is in line with previous studies (e.g., Davin, 2011; Kao, 2015; Moradian \& Baharvand, 2015; Nassaji \& Swain, 2000; Rahimi et al., 2015), offering some evidence showing that the knowledge coconstructed with the help of more capable others can contribute to moving learners toward further autonomous task-performance. In a similar vein, Swain (2000) highlighted that holding dialogues with others, especially more capable ones, could help learners co-shape a ZPD within which they can put their cognitive and linguistic resources together and resolve problems at hand jointly; in this way, they manage to not only resolve linguistic problems but also move toward self-regulation or 
autonomous performance. This also resonates with Vygotsky's (1978) assumption positing that graduated dialogic feedback can support learners to go beyond their solo abilities and take more control of the task at hand; that is, they are bolstered to move toward self-regulated task-performance. More recently, building upon Aljaafreh and Lantolf (1994), Poehner and Infante (2016) also highlighted that providing learners with dialogic feedback attuned to their level of need and responsiveness can support the learners to make further progress and nurture their emerging abilities.

Although all the participants in the study did not find the chance to function as primary interactants, the overall gains in the scores of all the students testify to the point that, being in the social space of the class, they also benefited from the collaborative dialogues between the teacher researcher and the addressed students. From this perspective, the findings of the study are supported by van Compernolle and Williams' (2013) position that unaddressed participants can benefit from social interactions in their milieu as far as they actively receive communicated information via involvement in private speech and embodied movements (e.g., gazing and head turning). In fact, as the qualitative analysis showed, some of the secondary interactants in each of the groups attempted to play and active role in receiving, regulating and internalizing the knowledge co-constructed through interaction between the teacher and directly addressed students. This active participation through private speech and embodied contributions helped the students form collective ZPDs and benefit from the exchanged dialogues (Poehner, 2009). There is growing evidence in sociocultural L2 research (Anani Sarab \& Gordani, 2015; De Guerrero \& Villamil, 2000; Lantolf \& Yanez-Prieto, 2003; Ohta, 2001) offering some evidence supporting the role that private speech can play in internalizing and regulating co-constructed knowledge on intermental plane. As a seminal study in this area, Ohta (2001) documented three different private speech types that Japanese adult learners were engaged in: vicarious response, repetition, and manipulation. Ohta (2001) argued that learners use private speech as a part of the internalization process when they endeavor to employ the social interactive resources of the L2.

The third research question of the study concerned the differential impact of cumulative and concurrent G-DA approaches on students' gains in English articles. Findings of the study indicated that the concurrent group ( $\mathrm{M}=9.27, \mathrm{SD}=1.25)$ outperformed the cumulative group ( $\mathrm{M}=7.26, \mathrm{SD}=2.68)$ on the post-test. Initially, this mean difference might be explicated by the fact that different ZPDs are present in the cumulative and concurrent groups (Lantolf, 2012) and this would result in one group outperforming the other. However, the outperformance of the concurrent group can be justified by the active participation of a larger number of learners in comparison to the cumulative group. Actually, one likely reason can be structural differences between the two G-DA approaches which led to imbalanced learner participation. As shown in the introduction section of the article, for concurrent G-DA, there is a quick role switching among students present in a class. That is, if one learner fails to provide an answer to the question raised by the teacher, then, the teacher asks for another student's help. On the other hand, in the cumulative G-DA, this is not the 
case and the teacher goes through a whole gamut of explicit-implicit hints in the form of an extended interaction with one learner before allocating the turn to another student (Poehner, 2009). Although this may be beneficial, only a limited number of students have the chance to serve as primary interactants. This has important consequences for students' classroom participation. In fact, in concurrent G-DA, ZPDoriented turns are not restricted to one learner, but the teacher calls upon various learners to co-construct a collective $\mathrm{ZPD}$ and resolve the problem at hand, and consequently, the learners are pushed to be on alert.

As substantiated by the qualitative analysis, a noticeable number of the students in the concurrent group $(n=23)$ pointed out that they served as active recipients through both verbal and non-verbal participation whereas the extent of those serving as an active recipient declined for cumulative group. That is, they did not actively tried to notice and internalize what was happening between primary interactants on the social level. As underscored by Lantolf and Thorne (2006), internalization is a process requiring active engagement of learners; they can facilitate internalization process by resorting to private speech (Anani Sarab \& Gordani, 2015) or embodied participation (van Compernolle \& Williams, 2013). By the same token, Swain, Huang, Barkaoui, Brooks, and Lapkin (2009) indicated that private speech can play a key role in internalization of co-shaped knowledge by serving some functions like establishing form-meaning relationship, stimulating mental retrieval, and monitoring learning processes. Moreover, bringing different students into the play so as to resolve one problem in the concurrent group stimulated a larger number of the students to be bodily active. That is, they were encouraged to shift their gazes or turn their heads toward the ones who were directly addressed. Hence, this embodied active reception enabled them to be actively engaged in receiving, integrating and internalizing the new knowledge co-built by interaction among the primary interactants (van Compernolle \& Williams, 2013).

\section{Conclusion}

Results of the current study showed that both approaches to G-DA were conducive to fostering learning English articles. However, the concurrent approach was more efficient in engaging learner in active participation and consequently, it resulted in higher gains in target forms. Active participation transpired in both forms of verbal and non-verbal languages. The results suggest that learners can benefit from the ZPD-sensitive feedback offered to unaddressed participants as far as they actively participate in the dialogues running at the inter-psychological plane. Internalization of the constructed or co-constructed knowledge does not occur automatically but learners need to realign their objectives with class objectives and participate in ZPDoriented sessions either overtly or covertly. Furthermore, active participation is not restricted to overt verbal contribution, but it can be accomplished by embodied movements such as gazing, turning heads, or eye-shifting. Learners' subvocal answers to the questions posed to the addressed participants, i.e., vicarious response (Ohta, 2001), was one of the most prevalent forms of active participation which was 
verified to be conducive to internalizing the knowledge shaped at inter-personal plane. Also, in concurrent approach learners are addressed more often and take primary interactant roles more with the result that they join their efforts together, go beyond group as context (Petrovsky, 1985), and work toward group as a psychological unit, a collective ZPD. In fact, concurrent approach pushes them to build on their physical proximity in class and co-construct the task at their hand by pooling their abilities together.

Moreover, findings of the study resonated with other studies (e.g., Aljaafreh \& Lantolf, 1994; Anton, 2009; Kao, 2015; Moradian \& Baharvand, 2015; Nassaji \& Swain, 2000; Poehner, 2009; Rahimi et al., 2015) that ZPD-sensitive feedback can help learner to build upon their current level of abilities and go beyond them by relying on the temporary crutch of offered feedback. In this study, through ZPDsensitive feedback, the learners could co-construct further awareness and knowledge about English articles and internalize it in intra-personal level.

Despite its contributions, there are some limitations to the present study which should be taken into account. This study lacked a non-DA or static group, so the results cannot be compared with non-DA approaches to assessment. Therefore, other studies can deepen and broaden our understanding into the effectiveness of G-DA approaches by including a control group and working in the context of private language institutes. Further, this study targeted only English articles so other studies can enrich our understanding about the use of G-DA approaches in developing other language skills and sub-skill.

Notwithstanding its shortcomings, the current study can present some implications for pertinent stakeholders. For instance, the findings can help teachers reconsider their views about active participation. That is, the teachers can develop the view that active participation is not restricted to the verbal contributions that learners make. Besides, in light of the qualitative data, the teachers are suggested to make their students aware of the roles that private speech can play in second language learning. Also, teacher educators can draw upon the growing amount of evidence supporting the role of G-DA and incorporate G-DA tenets into in-service and pre-service teacher education programs.

\section{References}

Ableeva, R. (2008). The effects of dynamic assessment on L2 listening comprehension. In J. P. Lantolf and M. E. Poehner (Eds.), Sociocultural theory and the teaching of second languages (pp. 57-86). London: Equinox Press.

Ableeva, R. (2010). Dynamic assessment of listening comprehension in L2 French. Unpublished doctoral dissertation. The Pennsylvania State University, University Park, PA.

Aljaafreh, A., \& Lantolf, J. P. (1994). Negative feedback as regulation and second language learning in the zone of Proximal development. Modern Language Journal, 78(4), 465-483. http://doi.org/cs3dz8

Anani Sarab, M. R., \& Gordani, Y. (2015). The role of private speech in cognitive regulation of learners: The case of English as a foreign language education. Cogent Education, 2(1), 1-10. 
Anton, M. (2009). Dynamic assessment of advanced language learners. Foreign Language Annals, 42 (3), 576-598.

Bitchener, J., \& Knoch, U. (2010). The contribution of written corrective feedback to language development: A ten month investigation. Applied Linguistics, 31(2), 193-214.

Bitchener, J. Young, S., \& Cameron, D. (2005). The Effect of Different Types of Corrective Feedback on ESL Student Writing. Journal of Second Language Writing, 14, 191-205.

Butler, Y. (2002). Second language learners' theories on the use of English articles. Studies in Second Language Acquisition, 24 (3), 451-480.

Davin, K. J. (2011). Group dynamic assessment in an early foreign language learning program: Tracking movement through the zone of proximal development. Unpublished doctoral dissertation. University of Pittsburgh. Retrieved January 29, 2013, from http://d scholarship.pitt.edu/7269/1/DAVINKJ_ETD.pdf

De Guerrero, M. C. M., \& Villamil, O. S. (2000). Activating the ZPD: Mutual scaffolding in L2 peer revision. Modern Language Journal, 84 (1), 51-68. http://doi.org/bm2kk5

DiCamilla, F., \& Anton, M. (2004). Private speech: a study of language for thought in the collaborative interaction of language learners. International Journal of Applied Linguistics 14(1), 36-69.

Donato, R. (1994). Collective scaffolding in second language learning. In J. P. Lantolf and G. Appel (Eds.), Vygotskian approaches to second language research (pp. 33-56). Norwood, NJ: Ablex.

Dornyei, Z. (2007). Research methods in applied linguistics. New York: Oxford University Press.

Ferris, D. R. (1999). The case for grammar correction in L2 writing classes: A response to Truscott. Journal of Second Language Writing, 8 (1), 1-11.

Guk, I., \& D. Kellogg. (2007). The ZPD and whole class teaching: Teacher-led and student-led interactional mediation of tasks. Language Teaching Research, 11 (3), 281-299.

Kao, Y. (2015). How interactive discussions support writing development: the application of Dynamic Assessment for learning Chinese rhetoric. Language Testing in Asia, 5(14), 1-16.

Lantolf, J. P. (2000). Introducing sociocultural theory. In J. P. Lantolf (Eds.), Sociocultural theory and second language learning (pp. 1-26). Oxford, England: Oxford University Press.

Lantolf, J. (2012). Sociocultural Theory: A Dialectical approach to L2 research. In S. M. Gass and A. Mackey (Eds.), Handbook of second language acquisition (pp. 57-72).

Lantolf, J. P., \& Poehner, M. E. (2004). Dynamic assessment of L2 development: Bringing the past into the future. Journal of Applied Linguistics, 1 (1), 49-72.

Lantolf, J. P., \& Poehner, M. E. (2014). Sociocultural theory and the pedagogical imperative in L2 education: Vygotskian praxis and the research/practice divide. London: Routledge.

Lantolf, J. P., \& Thorne, S. L. (2006). Sociocultural theory and the genesis of second language development. Oxford: Oxford University Press.

Lantolf, J. P., \& Yáñez-Prieto, C. (2003). Talking yourself into Spanish: Intrapersonal communication and second language learning. Hispania, 86 (1), 97-109.

Lidz, C. (1987). Dynamic assessment. New York: Guilford Press.

Mackey, A., \& Gass, S. M. (2005). Second language research: Methodology and design. Lawrence Erlbaum Associates, Publishers. Mahwah, New Jersey London.

Liu, D., \& Gleason, J. I. (2002). Acquisition of the article the by nonnative speakers of English: An analysis of four nongeneric uses. Studies in Second Language Acquisition, 24, 1-26.

Master, P. (1995). Consciousness raising and article pedagogy. In D. Belcher and G. Briane (Eds.), Academic writing in a second language: Essays on research and pedagogy (pp. 183204). New York: Ablex. 
McDonough, J., \& McDonough, S. (1997). Research methods for English language teachers. London: Arnold.

Moradian, M., \& Baharvand, P. (2015). The effect of group dynamic assessment on raising young Iranian EFL learners' metacognitive awareness and listening comprehension. English Language Teaching, 2(3), 67-86.

Nassaji, H., \& Swain, M. (2000). A Vygotskian perspective towards corrective feedback in L2: The Effect of random vs. negotiated help on the acquisition of English articles. Language Awareness, 9 (1), 34-51. http://doi.org/fbc2xk

Ohta, A. S. (2000). Rethinking interaction in SLA: Developmentally appropriate assistance in the zone of proximal development and the acquisition of L2 grammar. In J. P. Lantolf (Eds.), Sociocultural theory and second language learning (pp. 51-78). Oxford: Oxford University Press.

Ohta, A. S. (2001). Second language acquisition processes in the classroom: Learning Japanese. Mahwah, NJ: Lawrence Erlbaum Associates.

Petrovsky, A. V. (1985). Studies in psychology. The Collective and the individual. Moscow: Progress.

Poehner, M. E. (2007). Beyond the test: L2 dynamic assessment and the transcendence of mediated learning. Modern Language Journal, 91 (3), 323-340.

Poehner, M.E. (2008). Dynamic Assessment: A Vygotskian approach to understanding and promoting second language development. Berlin: Springer Publishing.

Poehner, M. E. (2009). Group dynamic assessment: Mediation for the L2 classroom. TESOL Quarterly, 43 (3), 471-491.

Poehner, M. E., \& Infante, P. (2016). Mediated development: A Vygotskian approach to transforming second language learner abilities. TESOL Quarterly. Advance online publication. doi: 10.1002/tesq.308.

Poehner, M. E., \& Lantolf, J. P. (2005). Dynamic assessment in the language classroom. Language Teaching Research, 9 (1), 1-33.

Poehner, M., \& Lantolf, J. (2010). Vygotsky's teaching-assessment dialectic and L2 education: The Case for dynamic assessment. Mind, Culture, and Activity, 17 (4), 312-330.

Poehner, M. E., \& van Compernolle, R. A. (2011). Frames of interaction in dynamic assessment: Developmental diagnoses of second language learning. Assessment in Education: Principles, Policy and Practice, 18 (2), 183-198.

Rahimi, M., Kushki, A., \& Nassaji, H. (2015). Diagnostic and Developmental potentials of dynamic assessment for L2 writing. Language and Sociocultural Theory, 2(2), 185-208.

Sheen, Y. (2007). The effect of focused written corrective feedback and language aptitude on ESL learners' acquisition of articles. TESOL Quarterly, 41(2), 255-283.

Shintani, N., Ellis, R., \& Suzuki, W. (2013). Effects of written feedback and revision on learners' accuracy in using two English grammatical structures. Language Awareness, 64 (1), 103-131.

Storch, N. (2010). Critical feedback on written corrective feedback research. International Journal of English Studies, 10 (2), 29-46.

Swain, M. (2000). The output hypothesis and beyond: Mediating acquisition through collaborative dialogue. In J. P. Lantolf (Eds.), Sociocultural theory and second language learning (pp. 97-114). Oxford, England: Oxford University Press.

Swain, M., Huang, L. S., Barkaoui, K., Brooks, L., \& Lapkin, S. (2009). The speaking section of the TOEFL iBT ${ }^{\mathrm{TM}}$ (SSTiBT): Test-takers' reported strategic behaviors (TOEFL iBT ${ }^{\mathrm{TM}}$ Research Series No. TOEFLiBT-10). Princeton, NJ: ETS. 
van Compernolle, R. A., \& Williams, L. (2012). Promoting sociolinguistic competence in the classroom zone of proximal development. Language Teaching Research, 16(1), 39-60.

van Compernolle, R. A., \& Williams, L., (2013). Group dynamics in language classroom: embodied participation as active reception in the collective Zone of Proximal Development. Classroom Discourse, 4(1), 1-21.

Vygotsky, L. S. (1978). Mind in society: The development of higher psychological processes. Cambridge: Harvard University Press.

Wells, G. (1999). Dialogic inquiry: Towards a sociocultural practice and theory of education. Cambridge, UK: Cambridge University Press.

\section{Copyrights}

Copyright for this article is retained by the author(s), with first publication rights granted to the Journal.

This is an open-access article distributed under the terms and conditions of the Creative Commons Attribution license (CC BY-NC-ND) (http://creativecommons.org/licenses/by-nc-nd/4.0/). 